radio and the weather has led to the discovery that the lowest layers of the atmosphere may sometimes bend radio wave tracks with a curvature exceeding that of the earth. Such abnormal refraction is associated with temperature inversions and marked water-vapour lapse-rates.

The use of radio-wave exploration for investigating the electrical state of the upper atmosphere has been the subject of continuous experiment in Britain since 1925. It has been found that the ionosphere is subject to a marked solar control, there being a general waxing and waning of the ionization densities in sympathy with the trend of the sunspot cycle. Transient radio echoes have also been noted from the levels of the lower ionosphere, and these have been traced to reflexions from meteor trails.

Finally, the use of sensitive short-wave receivers has disclosed the terrestrial reception of radio noise from both the sun and the stars. Sunspots are found to be powerful emitters of 5-metre waves, the emission being specially enhanced at times of visual solar flares. A continuous radio noise has also been identified as originating in the Milky Way. It is not yet known whether such galactic radio noise originates in interstellar space or in sunspot regions on the stars themselves.

\section{SCIENCE IN THE COLONIES}

$A^{n}$ FTER reviewing some of the historical examples of the application of research to Colonial problems, Dr. J. L. Simonsen, president of Section B (Chemistry), emphasizes that only with the help of men of science could many of these be solved. While agriculture must continue to be a main industry of the Colonies, its maximum development will require research of a high order. The Colonies can, however, no longer be regarded solely as prime producers, and the introduction of other industries deriving their raw materials from agriculture will be essential. In 1942 the Colonial Products Research Council was formed to review the field of Colonial raw materials, and by research methods ascertain how fuller use could be made of them.

Large-scale industry based on plant products must look to the most abundant of these, namely, the carbohydrates, starch and sugar, as its raw materials. Starch already finds an extended application in industry, and the methods devised at Birmingham for the separation of its two constituents, amylose and amylopectin, have now rendered these products readily accessible. A detailed survey of the littleknown starches of tropical Colonial countries is urgently needed. Although sucrose is the organic chemical produced on the largest scale, it has been little used as an industrial raw material apart from fermentation processes. The sucrose molecule is complex, and rapid progress of research into the production of substances of increased industrial value which is now being carried out in Great Britain and the United States cannot be expected, although some of these have been shown to have useful antifreeze, plastic and chemotherapeutic properties.

Recognition of the importance of microbiology has resulted in the decision of the Colonial Products Research Council to open a Microbiological Research Institute in Trinidad. Among the problems it is hoped to attack are those associated with soil fertility and the control of the Panama disease of bananas.
Synthetic organic chemistry has replaced many drugs previously obtained from plants; but this does not, however, diminish the need for a study by modern technique of the constituents of plants with which medicinal properties have been associated. Furthermore, it has been shown that the botanist can no longer disregard the nature of the chemical constituents in his classification of plants.

The value of improved methods of agriculture and the control of soil erosion will be neutralized if steps are not taken to prevent the large losses of the world's food supply incurred through pest infestation. If the new synthetic insecticides, D.D.T. and 'Gammexane', can be shown to be used with safety on foodstuffs, a weapon will be available which should largely eliminate this destruction by insect attack.

Of even greater importance is the control of two of the foremost insect enemies of man and animals, the mosquito and the tsetse fly. Experience with the new insecticide sprays against the mosquito indicates that the problem is not insoluble, and if by a coordinated attack on malaria in conjunction with the use of prophylactics, such as paludrine, meets with success, science will have made an outstanding contribution to Colonial prosperity. The control of tsetse, the transmitter of trypanosomiasis, presents a problem of far greater difficulty. The fly can be killed if brought into contact with insecticides, but it is not yet known how best this can be done. Possibly the use of smoke or smoke bombs from aircraft may be a solution; but the problem must be vigorously attacked on a scale commensurate with its magnitude.

\section{GEOLOGY IN THE DEVELOPMENT OF THE COALFIELDS}

$\mathrm{N}$ conformity with the general theme of 'swords into ploughshares', the presidential address to Section C (Geology) by Dr. Murray Macgregor deals with the place of geology in the development of the coalfields. The transference of the coal mines of Britain from private to public ownership has created an entirely new set of conditions, bringing with them their own complexities and hazards and demanding vigilant and unsparing service from all concerned. The unified industry will certainly require the best scientific and technical assistance that the country can give. Scientific research applied to the numerous problems that arise in connexion with the exploitation and utilization of the coal resources of Great Britain must be more directive and more closely integrated than in the past. There are the problems connected with occurrence, distribution, structure and correlation; with vertical and lateral variations in the number and thickness of seams, in the lithology, and in the fossil content; with the size and direction of faults, the amplitude and pitch of folds, the occurrence of suites of contemporaneous igneous rocks and of intrusions, etc. There are the chemical and physicochemical problems connected with the composition and classification of the coals, and the problems related to their preparation for the market and their economic use.

The fact that the geologist is the first link in this chain of concerted effort is too often overlooked or forgotten, and it must be emphasized that all development schemes, short-term and long-term alike, depend upon a proper and thorough knowledge and 